\title{
Quantitative Performance Analysis of Respiratory Facemasks Using Atmospheric and Laboratory Generated Aerosols Following with Gamma Sterilization
}

Special Issue:

Special Issue on COVID-19 Aerosol Drivers, Impacts and Mitigation (IX)

\section{Amit Kumar*, D.N. Sangeetha, Ramani Yuvaraj, M. Menaka, Venkatesan Subramanian, Balasubramanian Venkatraman}

Radiological and Environmental Safety Division, Indira Gandhi Centre for Atomic Research, Kalpakkam-603102, India

\section{ABSTRACT}

The emergence of the recent COVID-19 pandemic has rendered mandatory wearing of respiratory masks by infected persons, frontline workers, security personnel and members of the public. This has caused a sudden shift of focus, and significant demand on availability, effectiveness, reuse after sterilisation and development of facemask. Toward this, three types of masks viz. $\mathrm{N} 95$, non-woven fabric and double layer cotton cloth are being used by the majority of the population across the world as an essential inhalation protective measure for suppressing the entry of virus-laden respiratory droplets. The Filtering Efficiency $(F E)$ of these masks are tested for atmospheric and laboratory-generated aerosols of size $1.0 \mu \mathrm{m}$ and $102.7 \mathrm{~nm}$ particles before and after sterilisation and the two flow rate conditions corresponding to normal breath rate and during sneezing/coughing. Sterilisation is carried out using a gamma irradiator containing Co-60 source for the two-dose exposures viz. $15 \mathrm{kGy}$ and $25 \mathrm{kGy}$. The $F E$ of surgical and cloth masks is found to be in the range of $15.76 \pm 0.22$ to $22.48 \pm 3.92 \%, 49.20 \pm 8.44$ to $60 \pm 7.59 \%$ and 73.15 \pm 3.73 to $90.36 \pm 4.69 \%$ for aerosol sizes $0.3-5.0,1.0-5.0$ and 3.0-5.0 $\mu \mathrm{m}$ atmospheric aerosols respectively. The $F E$ of cloth and surgical masks ranges from $45.07 \pm 6.69 \%$ to $63.89 \pm 4.44 \%$ and $56.58 \pm 1.69 \%$ to $83.95 \pm 1.04 \%$ for $1.0 \mu \mathrm{m}$ laboratory-generated aerosol for two flow rate, control and irradiated conditions. The FE of N95 mask is found to be more than $95 \%$ for atmospheric aerosol, and $1.0 \mu \mathrm{m}$ laboratory-generated aerosol. However, $F E$ reduced to about $70 \%$ for most penetrating particle size after sterilisation. Further, FE reduced to $84 \%$ for the particle $>0.3 \mu \mathrm{m}$ and to $87 \%$ for the particle $<0.3 \mu \mathrm{m}$ after sterilisation. The reduction in $F E$ for $\mathrm{N} 95$ mask after sterilization is associated with the reduction of electrostatic interaction of filter medium with particles laden in the air stream. Instead of disposing of N95 masks after a single use, they can be reused a few times as N70 mask during this pandemic crisis after sterilisation. The use of cotton cloth masks in the general public serves fit for the purpose than surgical masks.

Keywords: COVID-19, N95 facemask, Non-woven fabric mask, Cloth mask, Gamma sterilization

\section{INTRODUCTION}

The corona virus disease (COVID-19) is a new type of disease that started spreading from December 2019 and presently, affected more than 200 countries across the territories around the globe. As of now (26 June 2020), more than 9 million positive cases and more than 0.4 million deaths indicate the severity of the current pandemic (Worldometer, 2020; https://www.worldometers.i nfo/coronavirus/). In general, the spread of the corona virus infection can occur through contact (direct and/or indirect), droplet spray in short-range (for droplet diameter greater than $5 \mu \mathrm{m}$ ) and long range by airborne transmission of aerosols (aerosol diameter less than $5 \mu \mathrm{m}$ ) when an infected person coughs, sneezes and talks. Further, the transport of droplet and aerosols depends 
on airflow velocity, temperature and relative humidity of the environment (Moriyama et al., 2020). According to the latest findings, the entry of COVID-19 virus into human tissue and from sneeze/cough droplet ballistics suggests that the significant transmission mechanism is not via the fine aerosols but by large droplets. This warrants the wearing of facemasks by everyone and maintaining reasonable social distance (more than $2 \mathrm{~m}$ ) to reduce the spread of the virus (Cheng et al., 2020; Eikenberry et al., 2020). Further, the particles generated from coughing/sneezing ranges from 0.1 to $100 \mu \mathrm{m}$ (Yang et al., 2007; Gralton et al., 2011; Lindsley et al., 2012) and these aerosols are the principal carrier of the virus. In general large droplet settle in a small distance about 1-2 m due to gravity (Morawska, 2006) however, aerosols remain suspended in the air for a longer time due to their small size, which plays a key role in spreading the infection (Morawska, 2020; Santarpia et al., 2020; Wang and Du, 2020). It is to be understood that inhalation hazard is the important means of getting infection; hence, in order to avoid or mitigate the spread of respiratory infection, the physical barrier such as facemask is highly necessary.

The facemask offers protection against infectious respiratory droplets, aerosols and corona virus-laden aerosols from the contaminated conditions (Feng et al., 2020; Ho et al., 2020). As millions of masks are being used daily, and currently, there exists a shortage of N95 masks (Juang et al., 2020). Hence, it has become necessary to reuse the masks in this pandemic crisis by the public, the staff of the frontline workers in health-care, and security personnel in order to avoid any shortages in the supply of N95 masks and prevent infection. It is often considered as good practice to sterilize the masks by killing the secondary pathogens before reusing. Many authorities (governments, manufacturers, scientists and experts) are looking to expand the availability of facemask by sterilizing them with an effective methods. Under these premises, multiple potential methods for sterilization have begun to be explored. Some are based on chemical methods (hydrogen peroxide, chlorine dioxide, bleach, alcohol, soap solution, ethylene oxide and ozone decontamination etc.) and physical methods (dry/steam heat treatment, UV light sterilization, electron beam and gamma irradiation etc.) (Kumar et al., 2015; Liao et al., 2020). All above sterilisation methods having advantages and disadvantages from one than others (Cramer et al., 2020; Juan et al., 2020). Among the different methods, the available literature seems to point out that, the most promising methods are those that use hydrogen peroxide vapour, ultraviolet radiation, moist heat, dry heat, ozone gas and gamma irradiation. The methods that are not recommended for disinfection or sterilization such as cleaning with soapy water, alcohol, bleach immersion, ethylene oxide, microwave, high temperature, and autoclave or steam because they can significantly degrade the filter due to degradation of the solidity of filter, alteration of the electrostatic properties of the filter fibre and affect particle penetration levels (Juan et al., 2020). Ozone gas appears to be effective in decontaminating respirator masks without damaging them, although it presents risks for the safety and health of workers who carry out the process if it is not handled properly (Zhang et al., 2004; Juan et al., 2020). In the case of dry or moist heat, at what temperature and how much time the mask should be heated, so that corona virus can be deactivated without affecting the filtering efficiency, filtering material, strap and strap attachment etc. is not known satisfactorily. Among all the sterilisation methods, the gamma irradiation is found to be safe, reliable and highly effective towards treating a wide variety of products with varying densities.

Radiation sterilization has been commonly used since the mid-nineteenth century to eliminate microorganisms, such as bacteria, fungi and spores, from medical equipment. Currently, almost half of the healthcare products, such as gloves, syringes and single-use protective clothing are sterilized using gamma irradiation, electron-beams or X-rays prior to use (IAEA, 2020). The gamma sterilisation has been extended to disinfect cloth masks and textile masks, which offer sizeable protection from respiratory droplet (IAEA, Technical report). The gamma radiation has the ability to penetrate products while sealed in their final packaging supports the manufacturing and distribution process by facilitating final packaged products as well as raw materials, by ensuring full and homogeneous sterility of the product (IAEA, 2020). It is found in some of the recent work on the COVID-19 pandemic scenario to determine whether radiation could be used for sterilization of facemasks (Cramer et al., 2020; Liao et al., 2020; Man et al., 2020; Tzu et al., 2020).

Towards these objectives, three types of masks, which are being mostly used across the world include, N95, non-woven fabric masks (often called as a surgical mask), self-made two-ply double layer cotton masks are tested for filtering efficiency by atmospheric aerosols and laboratory 
generated aerosols. The laboratory generated aerosols are $102.7 \mathrm{~nm}$ (the approximate size of the virus) and $1.0 \mu \mathrm{m}$ (the approximate size of droplets generated during sneezing and coughing). These masks are being used by the general public and are being worn in the open/office environment where they encounter aerosols available in the atmosphere. Hence, these masks were tested by general ambient/atmospheric aerosols. The testing was carried out in accordance with two breath conditions (normal breathing and during sneezing/coughing). As millions of masks are being used per day, in order to prevent the spread of secondary pathogens, cross contamination and continue to use the irradiated N95 face mask after sterilisation at par with surgical and cloth masks, filtering efficiency tests were conducted before and after sterilisation using gamma irradiation for the three types of masks. A comparison is made on the filtering efficiency of the current work and with the results available in the literature for N95 masks, in particular, in the present work, highlighting flow rate conditions, where, there is practically no data available. The detailed experimental methodology, results and discussion, conclusion and recommendations are described in this paper.

\section{MATERIAL AND METHODS}

The evaluation of the filtering efficiency of these masks are carried out in a test facility consisting of stainless steel cylindrical duct which has provision for fixing the facemask without any air leakage. The upstream and downstream aerosol number concentrations are counted, and the efficiency is determined before and after sterilisation of the masks. The details of the experimental setup, types and quantity of masks, necessary data acquisition system and generation of test aerosols are explained in this section.

\subsection{Experimental Setup}

All the tests were conducted at HEPA Filter Testing Laboratory, Radiological and Environmental Safety Division. The filter-testing rig was installed as per British Standards (BS-2831). The lab was accredited by NABL (National Accreditation Board for Testing and Calibration Laboratories), India and follows test procedure for HEPA filters used in nuclear industries as per IAEA technical document series 122. The schematic of the experimental filter test apparatus is shown in Fig. 1. It consists of a cylindrical tube of $8.5 \mathrm{~cm}$ internal diameter and $180 \mathrm{~cm}$ length connected with sampling ports in the upstream and downstream $(60 \mathrm{~cm}$ upstream and $30 \mathrm{~cm}$ downstream of the test specimen), aerosols generator, aerosols diagnostic instruments, air velocity meter, differential pressure monitor, relative humidity and temperature monitor of the air stream. The facemask specimen (without cutting the facemask) is fixed in the test rig using flange and O-ring setup, and it is perfectly found to be fitted without any air leakage (the mask edges were completely sealed). The desired airflow rates are achieved through suction by using an air displacement pump (Make: $\mathrm{M} / \mathrm{s}$. Rotovac and CG commercial motor) and flow meter (M/s. Weiser). The aerosols are sampled before (upstream) and after (downstream) of the specimen when aerosol-air suspension passes through the facemask. The effective area of the various masks during the test was $56.74 \mathrm{~cm}^{2}$.

\subsection{Aerosol Generator and Standard Test Aerosols}

All three types of masks are tested for filtering efficiency with atmospheric and laboratorygenerated aerosols. The standard test aerosols are generated using an aerosol generator (Model and Make: 7.811 and M/s Grimm Aerosol Technik, Germany). The aerosols suspended in air are continuously introduced at the inlet of the test rig. The polystyrene latex (PSL) particle sizes 1.0 $\pm 0.1 \mu \mathrm{m}$ (M/s MAGSPHERE Inc., USA) and $102.7 \pm 1.3 \mathrm{~nm}$ (M/s Polyscience Inc., USA) are used as monodispersed test aerosols.

\subsection{Aerosols Diagnostic Instruments}

The aerosol sampling is carried out from the upstream and downstream simultaneously using of Optical Particle Counter (OPC) (Model and Make: 1.108 and M/s Grimm Aerosol Technik, Germany) and Scanning Mobility Particle Spectrometer (SMPS) (Model and Make: 5.416 and M/s Grimm Aerosol Technik, Germany). The OPC works on the principle of light scattering and measures the particles in the range of $0.3-20 \mu \mathrm{m}$, and SMPS works on electrical mobility and 


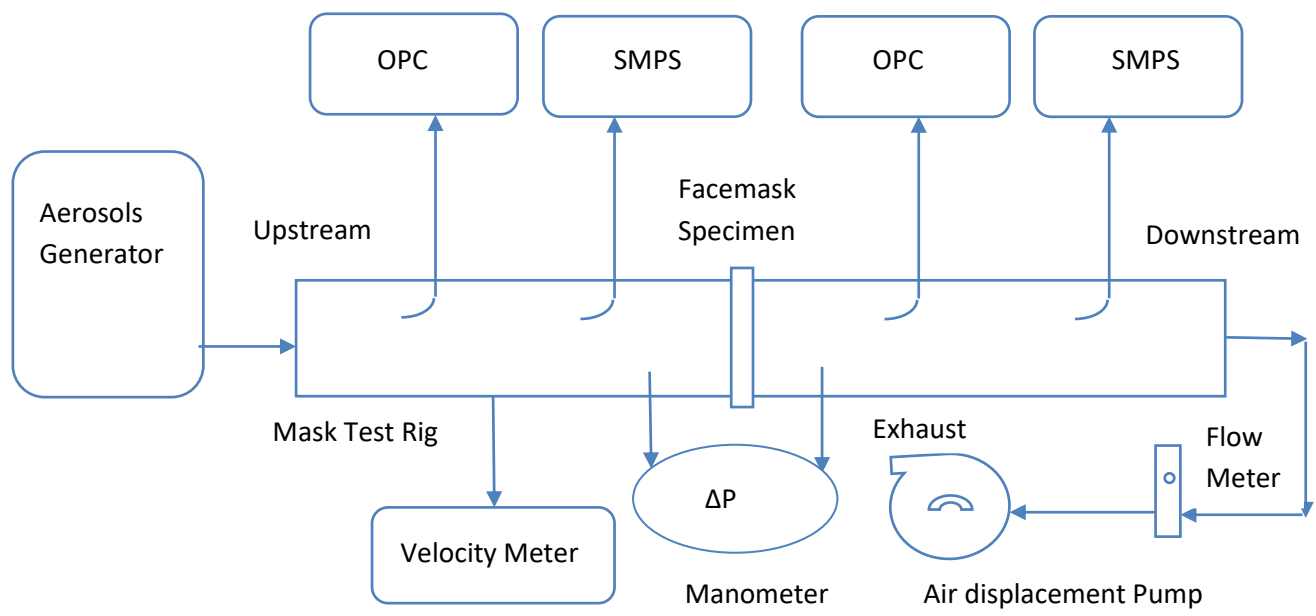

Fig. 1. Schematic of the experimental setup.

measures particles in the range of 10-1100 nm. The details of both instrument working principle and specification can be found elsewhere (Subramanian et al., 2019; Usha et al., 2019). The reproducibility of the OPC and SMPS are $\pm 3 \%$ and $\pm 5 \%$ respectively for the entire measuring range of OPC $(0.3-20 \mu \mathrm{m})$ and SMPS $(10-1100 \mathrm{~nm})$. The total upstream and downstream aerosols counts of the test rig were measured by OPC and SMPS without face mask for 20 and $90 \mathrm{~L} \mathrm{~min}^{-1}$ flow rate. The filter test rig was tested for zero efficiencies (without face mask) condition using ambient aerosols and found less than 3\% for OPC and ranges from 4-6\% for SMPS.

\subsection{Gamma Sterilisation}

The sterilization of various type of masks is achieved by using Gamma irradiation chamber (Model and Make: GC500 and M/s BRIT, India) where the masks are irradiated using Co-60 source (gamma energy 1.17 and $1.33 \mathrm{MeV}$ ) for the desired dose level. The gamma irradiation chamber is cylindrical in shape with approximately $17.2 \mathrm{~cm}$ in diameter, and $20.5 \mathrm{~cm}$ height and the dose throughout the chamber is uniform by using pencil sources. All facemasks were irradiated at a dose rate of $1.94 \mathrm{kGy} \mathrm{h}^{-1}$ (current activity $2.5 \mathrm{kCi}$ as of May 2020). The dose variability was $\leq 10 \%$, based on the most recent calibration by using Fricke dosimeter. It is noted from the recent study, the corona virus (SARS-COV and MERS-CoV) are inactivated with a cumulative radiation dose of 2.0 Mrad (Kumar et al., 2015; Feldmann et al., 2019). It is pointed out form the IAEA technical report (https://www.iaea.org/newscenter/pressreleases/radiation-effective-in-sterilizing-personalprotective-equipment-except-for-respiratory-masks-iaea), a high level disinfection with the dose in the range of 12-18 kGy would be enough to reduce $99.99 \%$ of the infectious agent. However, the sterilization is carried out as per the Technical document, BRIT, 2015, for the medical product with the cumulative dose in the range of 15-25 kGy.

\subsection{Types of Facemask and Quantity}

The three types of facemasks viz. N95 (NIOSH N95 TC -84A-6969, Manufacturing date: 01-022020), non-woven fabric (surgical mask) and self-made double layer cotton cloths (general public choice during the pandemic) have been tested for particulate filtering efficiency. The cotton masks are stitched from a bundle cloth made of $2 / 2$ twill weave (two warp threads crossing every two weft thread) having $80 \times 80$ counts per square inch. The surgical masks are made of 3 layered gauzes having high count gauze $(40 \times 24)$ at the outer side and two layers of normal gauze $(28 \times$ 24 counts) on the inner side. The tests are conducted at two constant flow rate conditions at 20 and $90 \mathrm{~L} \mathrm{~min}{ }^{-1}$ corresponding to breathing rate during light activity and sneezing/coughing respectively (Adams, 1993; Lee et al., 2019). The number of masks tested in each type is summarised in Table 1. The image of non-woven fabric, double layer cotton cloth and N95 facemask are shown in Fig. 2. A set of three $\mathrm{N} 95$ facemasks and 10 numbers of each of surgical and cloth masks are irradiated in gamma irradiator. The duration of irradiation is 7.75 , and $12.75 \mathrm{hrs}$ and total cumulative doses received by the masks are $15 \mathrm{kGy}$ and $25 \mathrm{kGy}$ respectively. 
Table 1. Number and type of masks tested for two exposure doses.

\begin{tabular}{llll}
\hline \multirow{2}{*}{ Type of facemask } & \multicolumn{3}{c}{ Gamma radiation dose } \\
\cline { 2 - 4 } & $0(\mathrm{kGy})$ & $15(\mathrm{kGy})$ & $25(\mathrm{kGy})$ \\
\hline Surgical mask (Nos.) & 20 & 10 & 10 \\
Cloth mask (Nos.) & 20 & 10 & 10 \\
N95 mask (Nos.) & 6 & 3 & 3 \\
\hline
\end{tabular}

Note: 0 kGy corresponds to control pieces (un-irradiated).

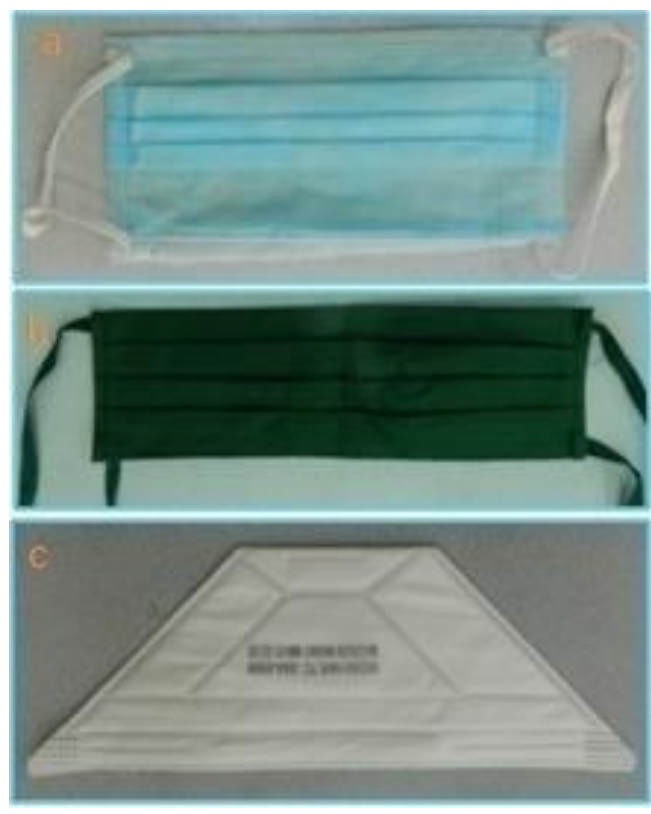

Fig. 2. Image of (a) non-woven fabric, (b) double layer cotton cloth and (c) N95 facemask.

\subsection{Data for Differential Pressure, Air Velocity, Relative Humidity and Temperature}

The pressure drop or differential pressure $(\triangle \mathrm{P})$ was measured using a manometer (Make and model: TSI, USA and 9565P143003) across the test mask at $10 \mathrm{~cm}$ away on either side. The measuring range and error in reading in $\Delta \mathrm{P}$ is -3736 to +3736 and \pm 2 pascal, respectively. The differential pressure is an indicator and condition for the comfort and breathability of a facemask. The face velocity in the test section is measured with a velocity meter (Make and model: Velocicalc, TSI, USA, and 9565P143003). The measuring range and error in reading in air face velocity is $0-50 \mathrm{~m} \mathrm{~s}^{-1}$ and $\pm 3 \%$ respectively. The face velocity of aerosols in the upstream is measured at $45 \mathrm{~cm}$ before the test specimen. The $\mathrm{K}$ type thermocouple and Humidity monitor are used for the measurement of temperature $(T)$ and relative humidity $(R H)$ of the air stream, respectively. The measuring range along with the error in the measurement of $\mathrm{T}$ and $\mathrm{RH}$ are -10 to $60^{\circ} \mathrm{C} \pm 0.3^{\circ} \mathrm{C}$ and 5 to $95 \% \pm 3 \%$ respectively.

\subsection{Filtration Efficiency}

The filtering efficiency $(F E)$ of three different masks are calculated using the following formula:

Filtering efficiency $(F E)=\left(C_{u}-C_{d}\right) \times 100 / C_{u}$,

where, $C_{u}$ and $C_{d}$ are the average aerosols concentration of upstream and downstream respectively for each size bin. The sampled data of each mask has been recorded for about 2$3 \mathrm{~min}$ in an interval of $6 \mathrm{~s}$ from OPC (total sample record 20-30) and for $21 \mathrm{~min}$ in an interval of 7 min from SMPS (total sample record 3). The FE is computed by taking the average of the collected data of upstream and downstream for the tested period and each filter. The $F E$ of the 
three types of the mask is calculated for atmospheric aerosols and monodispersed PSL aerosols of $1.0 \mu \mathrm{m}$. Further, the N95, cloth and surgical mask have been tested for $102.7 \mathrm{~nm}$ laboratorygenerated PSL aerosols and reported.

\subsection{Data Analysis}

In the present study, the aerosols number concentration is used to quantify the filtering efficiency of masks. The aerosols concentration recorded by instruments are analysed for each mask (N95, non-woven fabric (surgical mask) and self-made double layer cotton cloths) and FE was averaged for all similar type masks and tested conditions (like flow rate and gamma sterilization). Furthermore, the uncertainty associated with the $F E$ of the facemask has been calculated. Type A uncertainty has been arrived at for repeated measurement and number of face masks tested and Type B uncertainty has been calculated based on the following individual uncertainty (accuracy in measurement, resolution and calibration of the instrument). The combined uncertainty has been calculated and then expanded uncertainty has been derived from combined uncertainty by multiplying the coverage factor ( $95 \%$ confidence level). The average $F E$ was subjected to one iteration of the Grubbs test, with a $95 \%$ confidence interval to remove most one outlier in filtering efficiency. This improves the statistical variation of the data for the calculation of $F E$.

\section{RESULTS AND DISCUSSION}

The masks being tested is fixed into an air duct, and ambient particulates are flown through the facemask with a face velocity of $0.058 \pm 0.002$ and $0.264 \pm 0.009 \mathrm{~m} \mathrm{~s}^{-1}$ corresponding to 20 \pm 0.2 and $90 \pm 1.0 \mathrm{~L} \mathrm{~min}^{-1}$ flow rates respectively. The measured ambient air temperature is $26 \pm$ $0.3^{\circ} \mathrm{C}$, and $\mathrm{RH} \%$ is $65 \pm 3$. The measured average aerosol concentration for the upstream $\left(C_{u}\right)$ and two-flow rates 20 and $90 \mathrm{~L} \mathrm{~min}^{-1}$ is presented in Figs. 3(a) (SMPS) and 4(a) (OPC) respectively. Similarly, the average aerosols concentration measured for the downstream $\left(C_{d}\right)$ for two flow rate, with and without gamma sterilisation of N95 mask is shown in Figs. 3(b) (SMPS) and 4(b) (OPC) respectively. It is observed from Figs. 3(a) and 4(a) that, a significantly lower aerosol concentration in the upper size distribution for both the data sets, that is, for aerosol greater than $300 \mathrm{~nm}$ for the data measured by SMPS and greater than $5 \mu \mathrm{m}$ for the data measured by OPC. The data were excluded above these thresholds ( $300 \mathrm{~nm}$ for SMPS and $5 \mu \mathrm{m}$ for OPC) for all results presented in the paper due to the extremely low concentration, and this may increase statistical error. The pressure drop across all facemask is measured before and after sterilisation, and it is given in Table 2. The average pressure drop of surgical masks was found to be $2.45 \pm$ 2.03 pascal for $20 \mathrm{~L} \mathrm{~min}^{-1}$ flow rate and $7.36 \pm 2.08$ pascal for $90 \mathrm{~L} \mathrm{~min}^{-1}$ flow rate, which is much less than the reported value (approximately 20 pascals at a flow rate of $90 \mathrm{~L} \mathrm{~min}^{-1}$ ). The average pressure drop of cloth masks was found to be $11.57 \pm 2.12$ and $73.55 \pm 2.74$ pascals for 20 and $90 \mathrm{~L} \mathrm{~min}^{-1}$ flow rate, respectively. The average pressure drop of $\mathrm{N} 95$ mask was $31.32 \pm 2.31$ pascal for $20 \mathrm{~L} \mathrm{~min}^{-1}$ flow rate and $258.9 \pm 4.59$ pascal for $90 \mathrm{~L} \mathrm{~min}^{-1}$ flow rate. The average pressure drop of cloth masks is more than surgical masks and less than N95 masks. It is to be mentioned that the pressure drop across all the three types of decontaminated facemask showed that there is no measurable change observed, i.e., the change appears within the error bar values, i.e., there is no physical change in bulk density of face mask fibres/threads after decontamination. The pressure drop indicates the condition for usage during breathing and is found to be in the accepted range (inhalation and exhalation resistance limit is 343 and 245 pascal respectively) (Lin et al., 2020).

\subsection{Efficiency Evaluation with Ambient Aerosols size 0.3-5 $\mu \mathrm{m}$ Using OPC}

The average FE of the cloth masks, surgical masks and N95 masks for the two-flow rate condition and before and after gamma sterilisation ( 15 and $25 \mathrm{kGy}$ ) is tabulated in Table 3. Table 3 is drawn with three particle size bins viz. 0.3-5.0, 1.0-5.0 and 3.0-5.0 $\mu \mathrm{m}$. An average $F E$ of cloth masks vs. aerosol optical diameter is shown in Fig. 5 for control and decontaminated mask for two flow rates. It is observed from Fig. 5 and Table 3, in the case of cloth masks, average $F E$ is found to be more or less same after sterilisation and found to vary from $18.84 \pm 0.33-20.28 \pm 1.49 \%$, 
(a)

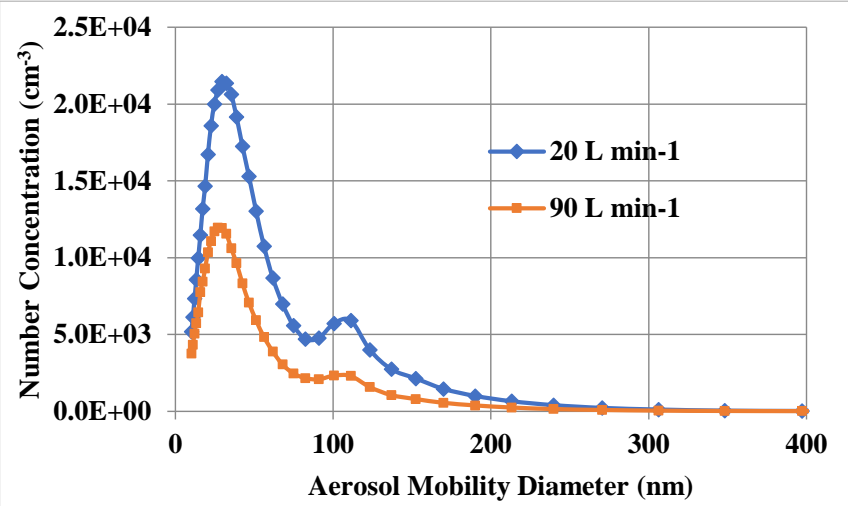

(b)

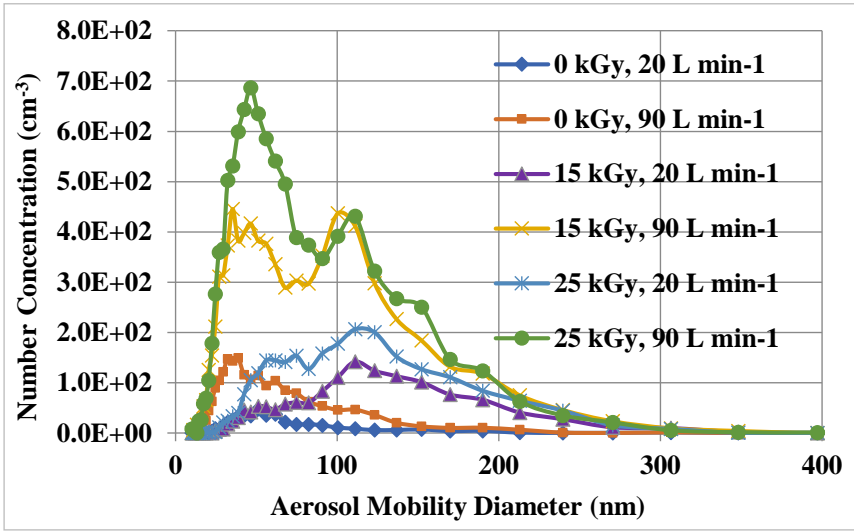

Fig. 3. (a) Upstream aerosols concentration as a function of mobility particle size measured by SMPS. (b) Downstream aerosols concentration as a function of mobility particle size measured by SMPS.

(a)

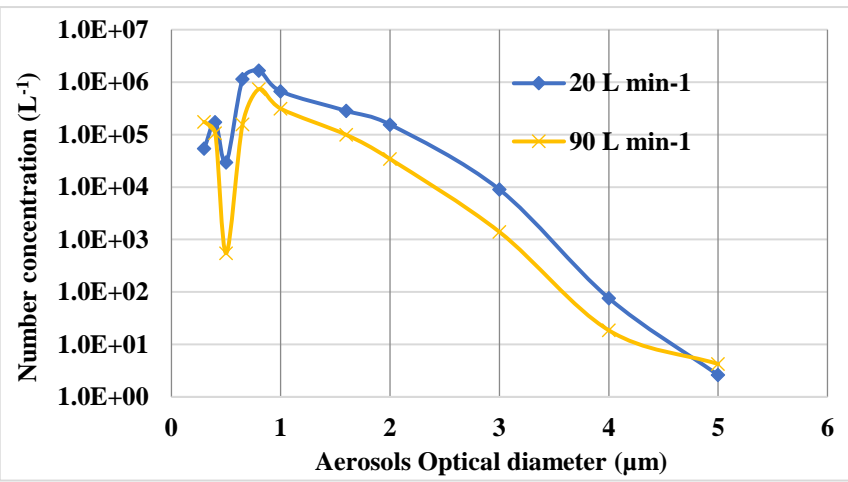

(b)

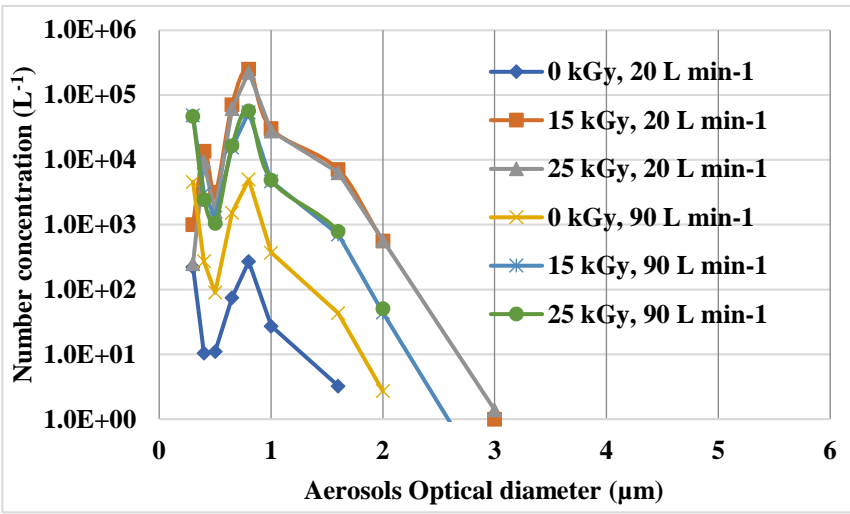

Fig. 4. (a) Upstream aerosols concentration as a function of optical particle size measured by OPC. (b) Downstream aerosols concentration as a function of optical particle size measured by OPC. 
Table 2. Pressure drop across the filter for two-flow rate condition.

\begin{tabular}{lllll}
\hline S. N. & Type of mask & Flow rate $\left(\mathrm{L} \mathrm{min}^{-1}\right)$ & $\Delta \mathrm{P}$ (pascal) for control masks & $\Delta \mathrm{P}$ (pascal) for sterilized masks \\
\hline 1. & N95 & 20 & $31.32 \pm 2.31$ & $30.89 \pm 2.64$ \\
& & 90 & $258.9 \pm 4.59$ & $257.7 \pm 3.59$ \\
2. & Surgical & 20 & $2.45 \pm 2.03$ & $2.95 \pm 1.83$ \\
& & 90 & $7.36 \pm 2.08$ & $7.16 \pm 1.78$ \\
3. & Cloth & 20 & $11.57 \pm 1.87$ & $12.78 \pm 2.12$ \\
& & 90 & $73.55 \pm 2.74$ & $72.95 \pm 1.74$ \\
\hline
\end{tabular}

Table 3. Filtration efficiency of three types of masks for two flow rate, control and irradiated mask for ambient aerosols.

\begin{tabular}{|c|c|c|c|c|c|c|c|}
\hline \multirow{4}{*}{ Mask Type } & \multirow{4}{*}{$\begin{array}{l}\text { Aerosols } \\
\text { Size in } \mu \mathrm{m}\end{array}$} & \multicolumn{6}{|c|}{ Gamma radiation dose } \\
\hline & & \multicolumn{2}{|c|}{0 (kGy) } & \multicolumn{2}{|c|}{$15(\mathrm{kGy})$} & \multicolumn{2}{|c|}{25 (kGy) } \\
\hline & & $20 \mathrm{~L} \mathrm{~min}^{-1}$ & $90 \mathrm{~L} \mathrm{~min}^{-1}$ & $20 \mathrm{~L} \mathrm{~min}^{-1}$ & $90 \mathrm{~L} \mathrm{~min}^{-1}$ & $20 \mathrm{~L} \mathrm{~min}^{-1}$ & $90 \mathrm{~L} \mathrm{~min}^{-1}$ \\
\hline & & \multicolumn{6}{|c|}{ Average FE $(\%) \pm$ Uncertainty } \\
\hline \multirow[t]{3}{*}{ Cloth } & $0.3-5.0$ & $20.28 \pm 1.49$ & $18.84 \pm 0.33$ & $20.44 \pm 1.68$ & $19.21 \pm 1.51$ & $19.74 \pm 1.92$ & $19.63 \pm 2.67$ \\
\hline & $1.0-5.0$ & $60.50 \pm 7.59$ & $49.20 \pm 8.44$ & $51.16 \pm 5.38$ & $53.51 \pm 5.09$ & $54.94 \pm 9.56$ & $59.09 \pm 4.03$ \\
\hline & $3.0-5.0$ & $87.44 \pm 8.99$ & $81.53 \pm 8.10$ & $80.66 \pm 4.28$ & $82.89 \pm 4.78$ & $88.90 \pm 7.14$ & $89.41 \pm 5.63$ \\
\hline \multirow[t]{3}{*}{ Surgical } & $0.3-5.0$ & $20.98 \pm 2.74$ & $20.08 \pm 2.87$ & $20.28 \pm 1.61$ & $15.76 \pm 0.22$ & $22.48 \pm 3.92$ & $17.48 \pm 0.52$ \\
\hline & $1.0-5.0$ & $59.22 \pm 9.25$ & $51.03 \pm 8.88$ & $50.12 \pm 2.55$ & $50.89 \pm 6.49$ & $56.85 \pm 5.58$ & $49.89 \pm 7.63$ \\
\hline & $3.0-5.0$ & $90.36 \pm 4.69$ & $80.19 \pm 8.33$ & $81.65 \pm 9.23$ & $77.68 \pm 12.21$ & $84.60 \pm 6.28$ & $73.15 \pm 3.73$ \\
\hline \multirow[t]{3}{*}{ N95 } & $0.3-5.0$ & $99.68 \pm 0.05$ & $94.98 \pm 1.98$ & $69.78 \pm 1.07$ & $63.12 \pm 2.22$ & $70.14 \pm 1.18$ & $65.44 \pm 2.48$ \\
\hline & $1.0-5.0$ & $99.51 \pm 0.59$ & $99.99 \pm 0.01$ & $99.67 \pm 0.52$ & $99.63 \pm 0.59$ & $99.57 \pm 0.45$ & $99.05 \pm 1.53$ \\
\hline & $3.0-5.0$ & $99.99 \pm 0.01$ & $99.99 \pm 0.01$ & $99.99 \pm 0.01$ & $99.99 \pm 0.01$ & $99.99 \pm 0.01$ & $99.99 \pm 0.01$ \\
\hline
\end{tabular}

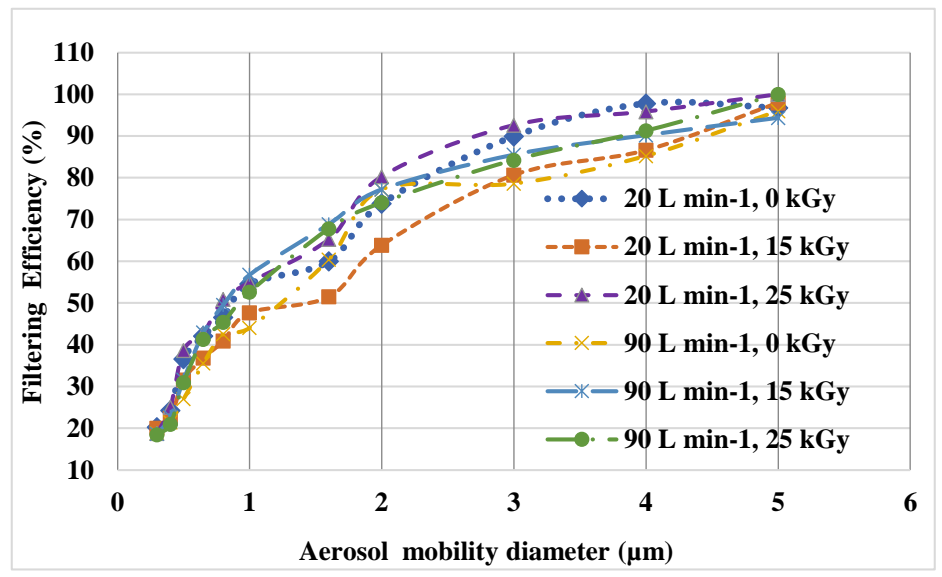

Fig. 5. Filtering efficiency of cloth mask as a function optical particle size with and without gamma sterilization and two-flow rate measured by OPC.

$49.20 \pm 8.44-60 \pm 7.59 \%$ and $80.66 \pm 4.28-89.41 \pm 5.63 \%$ for both flow rate and irradiated conditions for atmospheric aerosols of size $0.3-5.0,1.0-5.0$ and $3.0-5.0 \mu \mathrm{m}$ respectively. Similarly, from Table 3, the average filtering efficiency for the surgical mask found to vary from $15.76 \pm 0.22-22.48 \pm 3.92 \%, 49.89 \pm 7.63-59.22 \pm 9.25 \%$ and $73.15 \pm 3.73-90.36 \pm 4.69 \%$ for the atmospheric aerosols of size $0.3-5.0,1.0-5.0$ and $3.0-5.0 \mu \mathrm{m}$ respectively. The surgical masks are found to be performed with a slight decrease in efficiency after sterilisation when compared to without gamma sterilized condition for the same particle ranges. In the case of N95 masks, the filtering efficiency is found to be reduced to $69.78 \pm 1.07 \%$ from $99.68 \pm 0.05 \%$ and about 63.12 $\pm 2.22 \%$ from $94.98 \pm 1.98 \%$ for the two irradiated conditions for 20 and $90 \mathrm{~L} \mathrm{~min}^{-1}$ respectively. The uncertainty in FE is significantly more for cloth and surgical masks in case of 1.0-5.0 and 3.0$5.0 \mu \mathrm{m}$ aerosols compared to N95 masks probably indicating the texture/material quality of masks in the manufacturing stage. Further, the masks showed no measurable changes in fit or 
measurable structural changes when exposed up to $25 \mathrm{kGy}$ doses of radiation. The International Atomic Energy Agency (IAEA) has recently indicated the same observation that there is no significant change in the texture of the mask with respect to fit factor of the mask at $24 \mathrm{kGy}$ radiation dose, which is needed to kill viruses and bacteria (IAEA, 2020).

\subsection{Efficiency Evaluation with PSL Aerosol Size of $1.0 \mu \mathrm{m}$}

The performance evaluation of mask for atmospheric aerosols may give more statistical error due to low aerosols number concentration (less than $10^{1}-10^{2} \mathrm{~L}^{-1}$ ) for $1.0 \mu \mathrm{m}$ and above. In this regard, all three types of masks are tested for laboratory-generated PSL aerosols of size $1.0 \mu \mathrm{m}$. This kind of added information may be beneficial for some specific context and application. For example, the average number of aerosols generated per cough by Influenza patient is $7.5 \times 10^{4}$ and count median diameter (CMD) of cough generated aerosols/droplet were in between 0.6 to $0.9 \mu \mathrm{m}$ with Geometric Standard Deviation (GSD) 1.53 to 2.28 (Lindsley et al., 2012). Similarly, another recent study suggests that the average number of droplet/aerosols expelled per cough by a person having a respiratory infection is $4.9 \times 10^{6}$ with most of the aerosols are less than $5.0 \mu \mathrm{m}$, and the aerosol number becomes less when person recovered from the infection (Lee $e t$ al., 2019). Another study shows that $80 \%$ of droplets/aerosols are centred in the range of $0.74-$ $2.12 \mu \mathrm{m}$ during coughing and sneezing (Yang et al., 2007). Further, the detailed transmission of SARS-CoV-2 virus is not well understood till now; aerosols less than $5.0 \mu \mathrm{m}$ are considered as the primary source of transmission of respiratory infection (Doremalen et al., 2020; Wang et al., 2020). In this context, the filtering efficiency of the mask needs to be tested for high aerosols concentration $\left(10^{5}-10^{6} \mathrm{~L}^{-1}\right)$ in the $1.0 \mu \mathrm{m}$ range. Fig. 6 shows the filtering efficiency of these three types of filters for PSL particles of size $1.0 \mu \mathrm{m}$ with and without sterilisation and for the two flow rate conditions. It is observed from Fig. 6 that filtering efficiency for N95 mask shows greater than $96.25 \pm 0.67 \%$ even after sterilization for both the flow rate conditions. The filtering efficiency of the surgical mask is found to be in the range of $71.12 \pm 2.09-83.95 \pm 1.04 \%$ before sterilisation, and it reduced to $43.2 \pm 5.65-56.58 \pm 1.69 \%$ after gamma sterilisation. The measured filtering efficiency of cloth mask in the range of $55.82 \pm 4.56-63.89 \pm 4.44 \%$ before sterilisation and $45.07 \pm 6.69-59.68 \pm 0.79 \%$ after sterilisation. The cotton mask showed not much variation after sterilisation. The lower efficiency is attributed to the density of fibres in the non-woven type masks while the density of wrap and weft per unit area in the case of cloth mask. However, these masks are effective for the particles in size range of $1.0 \mu \mathrm{m}$ and above (about $50 \%$ efficiency). It is also to be noted that the filtration efficiency of all three types of the mask is more for $90 \mathrm{~L} \mathrm{~min}^{-1}$ flow rate for $1.0 \mu \mathrm{m}$ aerosol when compared to the $20 \mathrm{~L} \mathrm{~min}^{-1}$. This is due to higher filtration capability for micron-sized aerosols by impaction at a large flow rate condition.

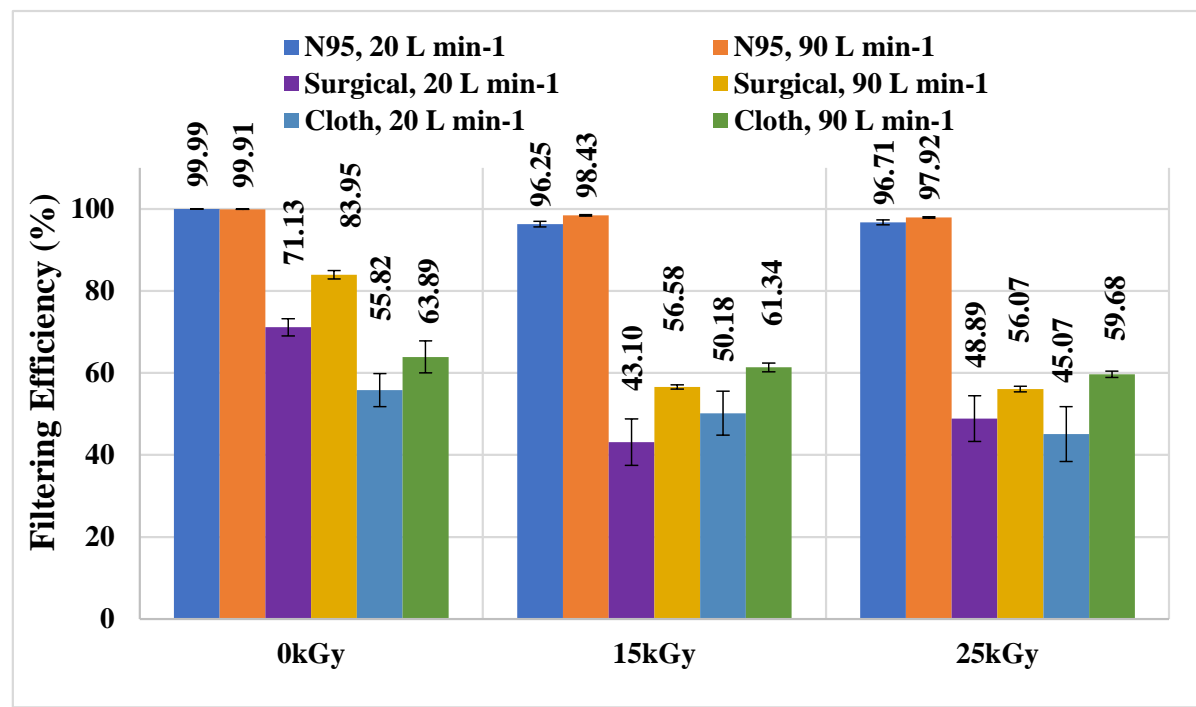

Fig. 6. Filtering efficiency of three types of masks with irradiation and two-flow rate for $1.0 \mu \mathrm{m}$ PSL aerosols. 


\subsection{Filtering Efficiency Evaluation of Facemask with $102.7 \mathrm{~nm}$ Aerosol}

The FE of $\mathrm{N} 95$ facemask has been evaluated for nano-sized laboratory-generated PSL aerosols. This gives added information and performance of masks in terms of $F E$ for nano-sized aerosols. This is also relevant in the present pandemic situation too, because transmission vector of COVID-19 infection takes place in ultrafine aerosol size and corona virus itself is in the range of 60-140 nm (Cascella et al., 2020; Kim et al., 2020). The N95, cloth and surgical facemasks are exclusively tested for $102.7 \mathrm{~nm}$ aerosols with a concentration in the order of $10^{4} \mathrm{~cm}^{-3}$. Fig. 7 shows an average FE of N95 mask for both un-irradiated, gamma sterilized and for two flow rate conditions. It can be seen from the figure that, the filtering efficiency is more than $98.02 \pm 0.15 \%$ for un-irradiated condition and both flow rates. The efficiency found to be reduced from $99.83 \pm 0.09 \%$ to 96.17 $\pm 0.99 \%$ for the flow rate of $20 \mathrm{~L} \mathrm{~min}^{-1}$ and $98.02 \pm 0.15 \%$ to $80.29 \pm 1.13 \%$ for $90 \mathrm{~L} \mathrm{~min}^{-1}$ under gamma-sterilized condition. The filtering efficiency for $90 \mathrm{~L} \mathrm{~min}^{-1}$ is found to be less when compared to $20 \mathrm{~L} \mathrm{~min}^{-1}$ condition (opposite to $1.0 \mu \mathrm{m}$ aerosols) where nano-sized particles are carried away due to high flow rate by the flow gas streamlines in the filtering media. Further, $F E$ of the cloth and surgical masks are also evaluated for nanoparticles. The FE of cloth masks is 20.59 $\pm 3.69 \%$ and $17.67 \pm 5.01 \%$ for $20 \mathrm{~L} \mathrm{~min}^{-1}$ and $90 \mathrm{~L} \mathrm{~min}^{-1}$ respectively. The variation in efficiency is not significant. The FE of surgical masks is $45.12 \pm 4.61 \%$ and $10.13 \pm 3.39 \%$ for $20 \mathrm{~L} \mathrm{~min}^{-1}$ and $90 \mathrm{~L} \mathrm{~min}^{-1}$, respectively. The variation in the efficiency is significant due to unstructured packing of fibres in the surgical mask, which paves the way for particles to trace the gas streamlines at a higher flow rate. The $F E$ of surgical masks is more than cloth masks for $102.7 \mathrm{~nm}$ aerosols for $20 \mathrm{~L} \mathrm{~min}^{-1}$ while in case of $90 \mathrm{~L} \mathrm{~min}^{-1}$ flow rate, the $F E$ of cloth masks is more compared to the surgical masks.

\subsection{Evaluation of Filtering Efficiency of N95, Cloth and Surgical Masks for Aerosols from $10 \mathrm{~nm}$ to $5.0 \mu \mathrm{m}$}

The filtering efficiency of N95, cloth and surgicalmasks are examined by combining data of OPC and SMPS covering from the range of $10 \mathrm{~nm}$ to $5 \mu \mathrm{m}$ sized aerosols. The evaluation in the lower size range may be useful for the users, who are working or interested in the filtration of nanoparticles in the facility like microelectronics fabrication environment. Further, as per ASTM standard, 2018, it is required to study the performance evaluation with respect to filtering efficiency less than $100 \mathrm{~nm}$ (ASTM standard, 2018). The FE of N95 mask under all conditions (unirradiated, gamma sterilised and for two flow rates) is shown in Fig. 8. The filtering efficiency of $\mathrm{N} 95$ mask shows a typical conventional $U$ shaped curve for aerosols ranging from $10 \mathrm{~nm}$ to $5.0 \mu \mathrm{m}$ with a minimum efficiency of control mask is $99.68 \pm 0.05 \%$ for $20 \mathrm{~L} \mathrm{~min}^{-1}$ and $94.98 \pm 1.98 \%$ for $90 \mathrm{~L} \mathrm{~min}^{-1}$ for $300 \mathrm{~nm}$ aerosols. The minimum efficiency of sterilised N95 mask is $69.78 \pm 1.07 \%$ for $20 \mathrm{~L} \mathrm{~min}^{-1}$ at $300 \mathrm{~nm}$ sized aerosols while $64.25 \pm 2.05 \%$ for $90 \mathrm{~L} \mathrm{~min}^{-1}$ in the range of 200$300 \mathrm{~nm}$ sized aerosols. The filtering efficiency is more for $20 \mathrm{~L} \mathrm{~min}^{-1}$ than $90 \mathrm{~L} \mathrm{~min}^{-1}$ in all the three respective conditions i.e. for the control, $15 \mathrm{kGy}$ and $25 \mathrm{kGy}$. It is known that the aerosol filtration takes place by five basic mechanisms viz. gravitational settling, inertial impaction,

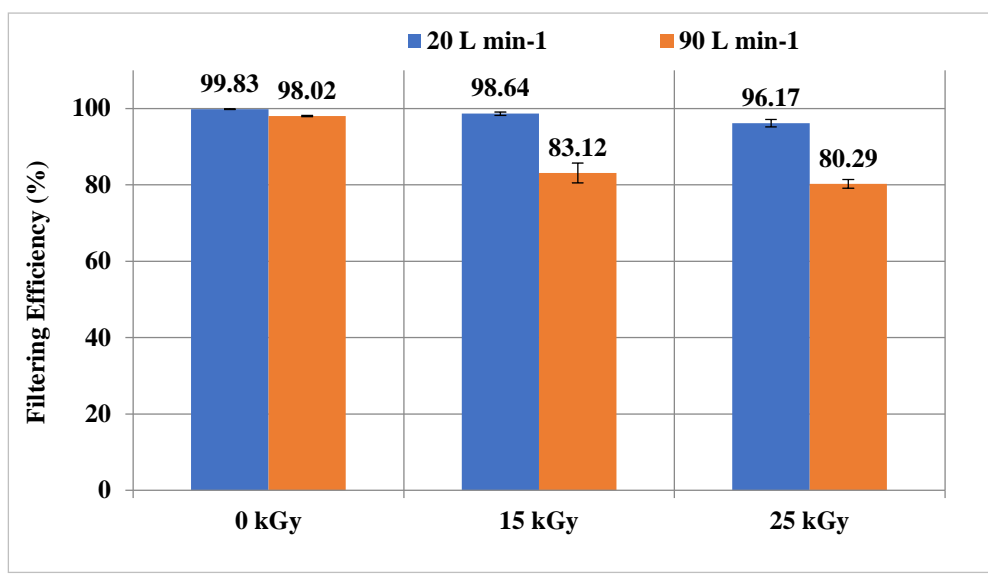

Fig. 7. N95 facemask filtering efficiency for $102.7 \mathrm{~nm}$ PSL aerosols. 


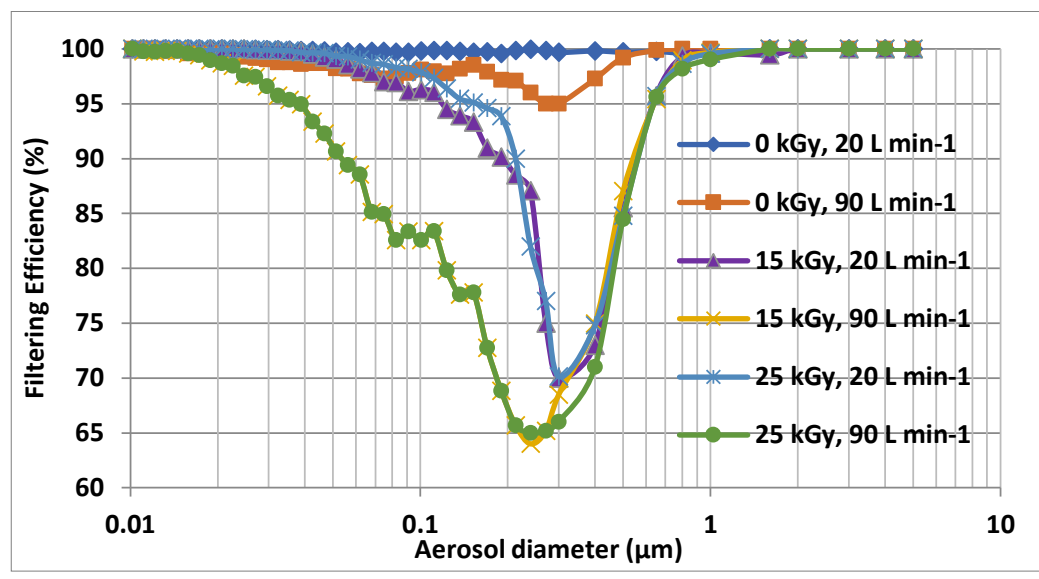

Fig. 8. Filtering efficiency of N95 mask for the aerosols of size ranging from $10 \mathrm{~nm}$ to $5 \mu \mathrm{m}$, for $15 \mathrm{kGy}$ and $25 \mathrm{kGy}$ dose exposure and the two flow rates 20 and $90 \mathrm{~L} \mathrm{~min}^{-1}$.

interception, diffusion and electrostatic interaction (Hinds, 1999; Vincent, 2007). The gravitational and impaction settling plays a major role in filtering the aerosols larger than $1.0 \mu \mathrm{m}$. As aerosol size decreases in the range of 0.1 to $1.0 \mu \mathrm{m}$, the Brownian diffusion and mechanical interception are the predominant mechanisms and for aerosols size, less than $0.1 \mu \mathrm{m}$, which can easily slip from filtering media, are captured predominately by electrostatic attraction in addition to the mechanical processes. The $\mathrm{N} 95$ mask consists of electrostatic filtration media which encompass a broad class of materials that are capable of capturing and retaining fine airborne particulates through electrostatic interaction (Coulomb and dielectrophoretic forces) in addition to mechanical processes (Impaction, settling, Interception and Diffusion) (Myers and Arnold, 2003). It is known that least efficiency is associated with particles in the range of $0.1-0.3 \mu \mathrm{m}$ that is bigger for diffusion and smaller for interception; hence, the $99 \%$ efficiency is achieved for this range by electrostatic interaction. When the media loses its charges, the particles are captured only by mechanical processes where the efficiency is reduced from 99\% to 65\% (Fig. 8 and Table 3). In the case of $1.0 \mu \mathrm{m}$ particles, the efficiency is not found reduced even after gamma irradiation (Fig. 8 and Table 3). Further, the N95 masks are designed for filtering efficiency more than 95\% of aerosols size greater than Most Penetration Particle Sizes (MPPS), and therefore, their underperformance below MPPS is not surprising results (Balazy et al., 2005, 2006). The FE of mechanical filters has the least efficiency at MPPS and increases with increase or decrease of aerosol size from MPPS.

The $F E$ of cloth and surgical masks has been investigated for two flow rates and is shown in Fig. 9. The $F E$ of both cloth and surgical masks shows a typical conventional filtering curve for aerosols ranging from $10 \mathrm{~nm}$ to $10 \mu \mathrm{m}$. The $F E$ is less for $90 \mathrm{~L} \mathrm{~min}^{-1}$ flow rate when compared to the $20 \mathrm{~L} \mathrm{~min}^{-1}$ for both cloth and surgical masks. The minimum FE of cloth masks is $14.27 \pm 2.85 \%$ for $90 \mathrm{~L} \mathrm{~min}^{-1}$ and $4.32 \pm 1.35 \%$ for $20 \mathrm{~L} \mathrm{~min}^{-1}$ for the aerosols in the range of 50-150 $\mathrm{nm}$ and 60$80 \mathrm{~nm}$ respectively. Similarly, the minimum $F E$ of surgical masks is $22.59 \pm 3.05 \%$ for $90 \mathrm{~L} \mathrm{~min}^{-1}$ and $12.54 \pm 1.51 \%$ for $20 \mathrm{~L} \mathrm{~min}^{-1}$ for $300 \mathrm{~nm}$ and $200 \mathrm{~nm}$ aerosols, respectively. The $F E$ of cloth and surgical masks increases with an increase of optical diameter and decrease of mobility diameter from least efficient MPPS, and the value of MPPS is lower for high flow rate compared to the low flow rate.

\subsection{Comparison of N95, Cloth and Surgical Mask Filtering Efficiency for Total Test Aerosols Concentration of Sizes $<300$ and $>300 \mathrm{~nm}$}

The filtering characteristics of any mask depend much on aerosol characteristics like diameter, charge and density of aerosols, the concentration of aerosols and airflow velocity (flow rate) apart from filter characteristics. Here, we have compared the FE of the $\mathrm{N} 95$ mask for total test aerosols concentration in sizes less than $300 \mathrm{~nm}$ and greater than $300 \mathrm{~nm}$. The total measured aerosols number concentration is in the order of $10^{3} \mathrm{~cm}^{-3}$ and $10^{4} \mathrm{~cm}^{-3}$ for aerosol sizes $>300 \mathrm{~nm}$ 


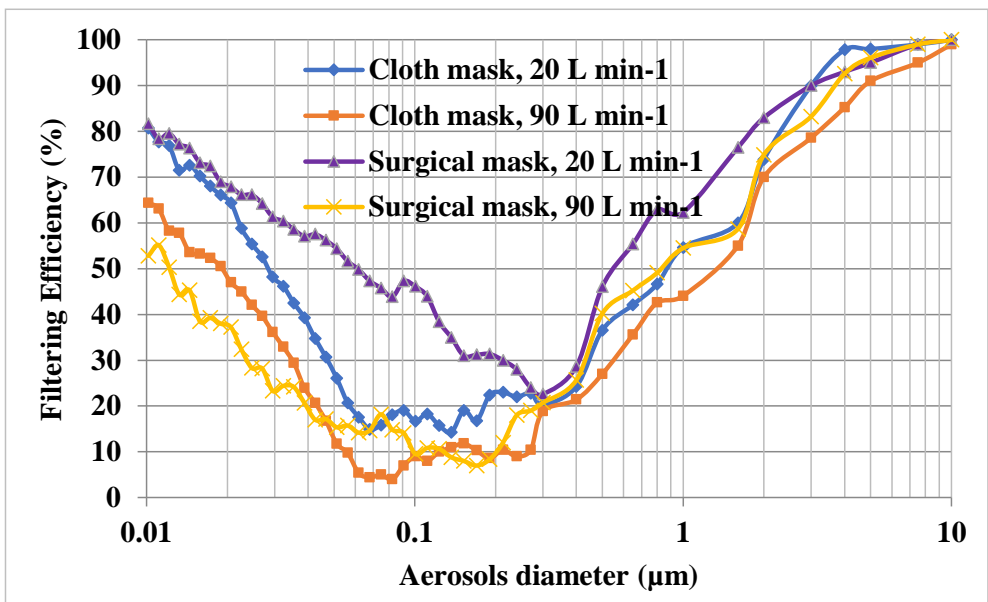

Fig. 9. Filtering efficiency of cloth and surgical mask for the aerosols of size ranging from $10 \mathrm{~nm}$ to $10 \mu \mathrm{m}$, for the two flow rates 20 and $90 \mathrm{~L} \mathrm{~min}^{-1}$.

Table 4. Comparison of N95 mask filtering efficiency for the total concentration of aerosols sizes $<300$ and $>300 \mathrm{~nm}$ for twoflow rate, control and after sterilization.

\begin{tabular}{|c|c|c|c|c|}
\hline \multirow{3}{*}{$\begin{array}{l}\text { Gamma irradiation } \\
\text { dose }\end{array}$} & \multicolumn{4}{|c|}{ Aerosol filtering efficiency with Uncertainty (\%) } \\
\hline & \multicolumn{2}{|c|}{ Flow rate $20 \mathrm{~L} \mathrm{~min}^{-1}$} & \multicolumn{2}{|c|}{ Flow rate $90 \mathrm{~L} \mathrm{~min}^{-1}$} \\
\hline & $0.3-5.0 \mu \mathrm{m}$ & $10-300 \mathrm{~nm}$ & $0.3-5.0 \mu \mathrm{m}$ & $10-300 \mathrm{~nm}$ \\
\hline $0 \mathrm{kGy}$ & $99.98 \pm 0.01$ & $99.89 \pm 0.03$ & $99.31 \pm 0.05$ & $98.92 \pm 0.12$ \\
\hline $15 \mathrm{kGy}$ & $84.28 \pm 1.68$ & $99.51 \pm 0.21$ & $91.02 \pm 1.17$ & $95.49 \pm 0.89$ \\
\hline $25 \mathrm{kGy}$ & $86.54 \pm 1.63$ & $99.04 \pm 0.11$ & $89.07 \pm 1.15$ & $96.16 \pm 1.13$ \\
\hline
\end{tabular}

$(0.3-5.0 \mu \mathrm{m})$ and $<300(10-300 \mathrm{~nm}) \mathrm{nm}$ respectively. Table 4 gives FE of N95 masksfor two-flow rate conditions for the masks, including control and after sterilization. The $F E$ is found to be $\geq 99 \%$ for particles sized $>300 \mathrm{~nm}$ and $<300 \mathrm{~nm}$ for both the flow rates. The $F E$ reduces after sterilisation from $99.98 \pm 0.01$ to $84.28 \pm 1.68 \%$ and $99.89 \pm 0.03$ to $99.04 \pm 0.11 \%$ for particles $>300 \mathrm{~nm}$ and $<300 \mathrm{~nm}$ respectively for fixed $20 \mathrm{~L} \mathrm{~min}^{-1}$ flow rate. In the case of $90 \mathrm{~L} \mathrm{~min}^{-1}$ flow rate, the $F E$ of the mask is reduced after sterilisation from $99.31 \pm 0.05$ to $89.07 \pm 1.15 \%$ and $98.92 \pm 0.12$ to $95.49 \pm 0.89 \%$ for particles $>300 \mathrm{~nm}$ and $<300 \mathrm{~nm}$ respectively. The reduction is found to be more for particles $>300 \mathrm{~nm}$ aerosols when compared to that of $<300 \mathrm{~nm}$ aerosol for both flow rates. The $\mathrm{N} 95$ mask performed most efficiently for low flow rate and nano-sized aerosols even after gamma sterilization. The electrostatic filters are efficient for nano-sized aerosols at low airflow velocity (flow rate) rather than high airflow velocity (Colbeck and Lazaridis, 2014).

The $F E$ of cloth mask is $46.76 \pm 2.58 \%$ and $36.58 \pm 2.87 \%$ for 20 and $90 \mathrm{~L} \mathrm{~min}^{-1}$ respectively for particles $<300 \mathrm{~nm}$. Similarly, the $F E$ of surgical masks is $63.82 \pm 1.78 \%$ and $28.75 \pm 1.52 \%$ for 20 and $90 \mathrm{~L} \mathrm{~min}^{-1}$ respectively, for particles $<300 \mathrm{~nm}$. The $F E$ of surgical masks is more compared to the cloth mask for $<300 \mathrm{~nm}$ aerosol size and $20 \mathrm{~L} \mathrm{~min}^{-1}$ flow rate while for $90 \mathrm{~L} \mathrm{~min}^{-1} \mathrm{FE}$ of cloth mask is more. The $F E$ of cloth and surgical masks is more for $<300 \mathrm{~nm}$ aerosol size compared to the $>300 \mathrm{~nm}$ for both flow rates.

\subsection{Observation of Morphological Change by Optical Microscope}

The fiber structure of N95 and surgical masks are examined in the optical microscope (Make and Model: Axioplan 2 Imaging, Metasystems, Germany) under 100X magnification. The image taken by an optical microscope for N95 and surgical mask is shown in Figs. 10 and 11, respectively. The dimension of each image is $65 \mu \mathrm{m} \times 65 \mu \mathrm{m}$, and the filter fibre diameter is in sub-micrometre range for $\mathrm{N} 95$ mask while micrometre range for the surgical mask. It is observed from Figs. 10(a), 10(b) and 10(c) that, no observable and significant change in morphology of filter fibre is found with gamma sterilisation upto $25 \mathrm{kGy}$ doses. Similar observations were reported by Scanning 


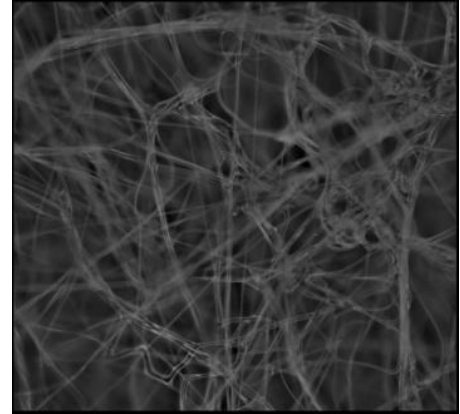

(a) Control

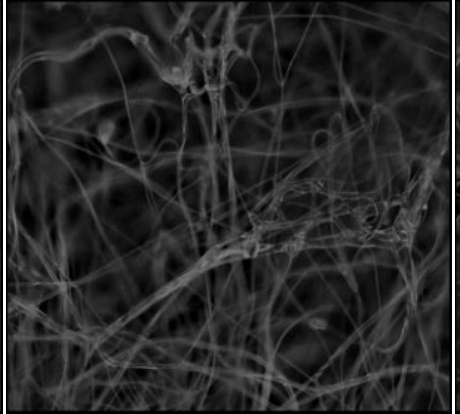

(b) 15 kGy

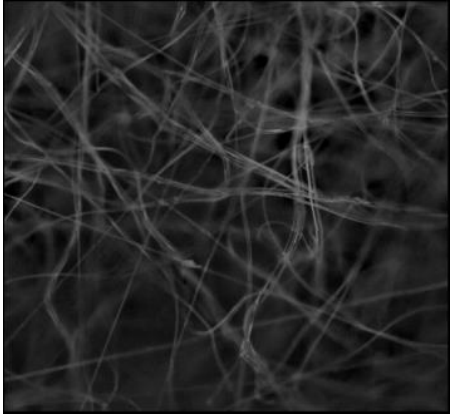

(c) $25 \mathrm{kGy}$

Fig. 10. Optical microscope image of inner layer fibre of N95 mask (a) control, (b) 15 kGy and (c) $25 \mathrm{kGy}$.
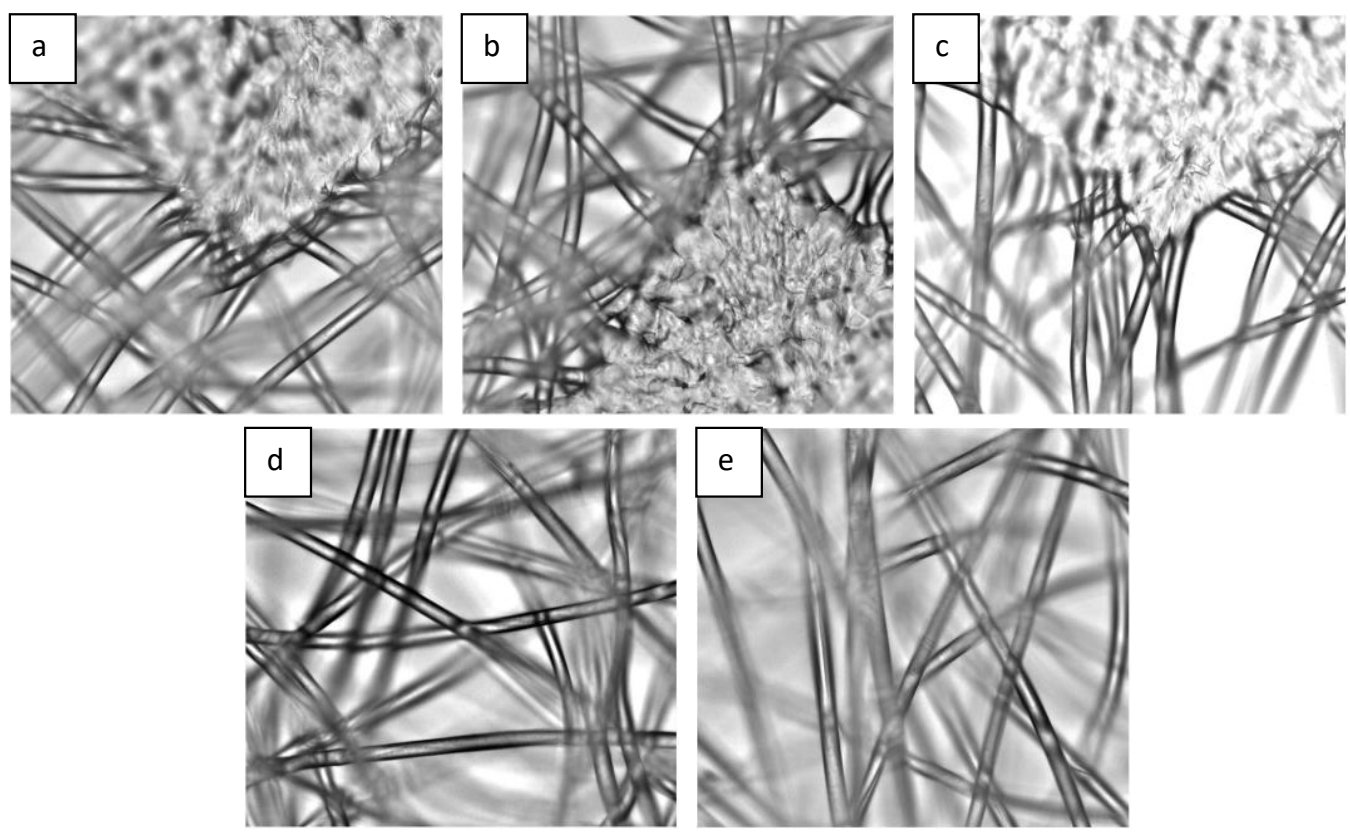

Fig. 11. Optical microscope image of three layers control surgical mask (a) repellent, (b) filter medium, (c) absorbent and filtering media of sterilised mask (d) $15 \mathrm{kGy}$ and (c) $25 \mathrm{kGy}$.

Electron Microscopy (SEM) up to $61 \mathrm{kGy}$ doses (IAEA technical report). The surgical mask consists of three layers viz. repellant the outer coloured layer, the filter medium in the middle and absorbent at the innermost layer. Figs. 11(a), 11(b), 11(c) are the microscopic image of repellant, filter media and absorber of the control mask respectively and Figs. 11(d) and 11(e) belong to the filter medium exposed to $15 \mathrm{kGy}$ and $25 \mathrm{kGy}$. It is observed from Figs. 11(a), 11(b) and 11(c) that, the structure of the filter fibre media is bonded together by using chemical adhesive and appeared entangled structure. It is observed from Figs. $10(\mathrm{~d})$ and $11(\mathrm{e})$ that, there is no observable change in the structure of the filter fibre after gamma sterilisation.

\subsection{Comparison of N95 Mask Filtering Efficiency from Literature after Gamma Sterilisation}

A comparison of filtering efficiency of N95 respiratory mask with various works from the literature under gamma-sterilized condition is summarized in Table 5 (Cramer et al., 2020; Lin et al., 2020; Man et al., 2020). It can be seen from the table that, the irradiation dose for mask sterilization is varied from 1.0 to $50 \mathrm{kGy}$, and mask efficiency has been tested for aerosols ranging from 0.1 to $1.0 \mu \mathrm{m}$. The reduction in efficiency is found to be more for most penetrating particle size $(0.3 \mu \mathrm{m})$ in all the cases. Among all the works carried out, the work of Cramer et al. (2020) 
Table 5. Comparison of $\mathrm{N} 95$ respiratory mask filtering efficiency from literature.

\begin{tabular}{|c|c|c|c|c|c|c|}
\hline \multirow{2}{*}{$\begin{array}{l}\text { Authors } \\
\text { Cramer et al., } 2020\end{array}$} & \multirow{2}{*}{$\begin{array}{l}\text { Expt. Parameters } \\
\mathrm{U}: 0.4 \mathrm{~m} \mathrm{~s}^{-1}\end{array}$} & \multirow{2}{*}{$\begin{array}{l}\text { Irradiation Dose } \\
\text { Aerosols size }(\mu \mathrm{m})\end{array}$} & & \multicolumn{3}{|c|}{ Filtering efficiency (\%) } \\
\hline & & & & 0.3 & 0.5 & 1.0 \\
\hline & $\mathrm{T}: 22.9-23.9^{\circ} \mathrm{C}$ & $0 \mathrm{kGy}$ & & 85.9 & 89.5 & 94.3 \\
\hline & $\mathrm{RH}: 11.3-21.4 \%$ & $1 \mathrm{kGy}$ & & 29.2 & 41.1 & 70.3 \\
\hline & $\Delta \mathrm{P}: 174-192$ pascal & 10 kGy & & 28.6 & 38.6 & 74.3 \\
\hline & & 50 kGy & & 24.8 & 36.7 & 69.5 \\
\hline \multirow[t]{4}{*}{ Man et al., 2020} & \multirow{4}{*}{$\begin{array}{l}\text { Parameters were not mention } \\
\text { in the paper }\end{array}$} & Aerosols size $(\mu \mathrm{m})$ & & 0.3 & 0.5 & 1.0 \\
\hline & & $0 \mathrm{kGy}$ & & 99.4 & 99.8 & 99.8 \\
\hline & & 10 kGy & & 55.4 & 79.1 & 98.1 \\
\hline & & $25 \mathrm{kGy}$ & & -- & 57.5 & 98.7 \\
\hline \multirow[t]{4}{*}{ Current work } & $\mathrm{U}: 0.066 \mathrm{~m} \mathrm{~s}^{-1}$ & Aerosols size $(\mu \mathrm{m})$ & 0.1 & 0.3 & 0.5 & 1.0 \\
\hline & $\mathrm{T}: 25-27^{\circ} \mathrm{C}$ & $0 \mathrm{kGy}$ & 99.8 & 99.7 & 99.8 & 99.9 \\
\hline & RH: $65-67 \%$ & 15 kGy & 98.6 & 70.1 & 86.7 & 96.3 \\
\hline & $\Delta \mathrm{P}: 31.32 \pm 2.31$ pascal & $25 \mathrm{kGy}$ & 96.2 & 68.5 & 87.9 & 96.7 \\
\hline \multirow[t]{3}{*}{ Lin et al., 2020} & $\mathrm{~T}: 38 \pm 2.5^{\circ} \mathrm{C}$ & Aerosols size $(\mu \mathrm{m})$ & \multicolumn{4}{|c|}{$0.007-0.882,(\mathrm{CMD}-0.075)$} \\
\hline & $\mathrm{RH}: 85 \pm 5 \%$ & $0 \mathrm{kGy}$ & \multicolumn{4}{|c|}{$>95$} \\
\hline & $\Delta \mathrm{P}:$ 59-75 pascal & 10,25 and $30 \mathrm{kGy}$ & \multicolumn{4}{|c|}{$44-77$} \\
\hline
\end{tabular}

showed the highest reduction in efficiency under gamma-sterilized condition. This may be due to their filtering media and relatively large face velocity $\left(0.4 \mathrm{~m} \mathrm{~s}^{-1}\right)$, as the control mask itself is showing 5-15\% less efficiency from others works. The filtering efficiency of present work and by Man et al. (2020) is found to have similarity for particles $>0.3 \mu \mathrm{m}$, but here also, at what flow rate that masks have been tested is not mentioned. It is noted that in all the works, the testing flow rate has mentioned in a few works. However, it is essential to test the masks under breathing rate condition towards fit for the purpose and that condition, is followed in our work. The Lin et al. (2020), has presented his work for aerosol size distribution ranging from 7-882 nm with CMD around $75 \mathrm{~nm}$ and FE of $\mathrm{N} 95$ mask was found to be $44-77 \%$ after gamma sterilization, which is much less than that of present work.

\section{SUMMARY AND CONCLUSION}

Three types of facemask viz. N95, surgical mask and self-made double layer cloth mask have been tested for particulate filtering efficiency for two-flow rate condition viz. 20 and $90 \mathrm{~L} \mathrm{~min}^{-1}$ before and after gamma sterilization using atmospheric aerosols in size range of $0.3-5 \mu \mathrm{m}$ and laboratory-generated aerosols of size $1.0 \mu \mathrm{m}$ and $102.7 \mathrm{~nm}$ (PSL). The sterilization was carried out for two-dose condition viz. $15 \mathrm{kGy}$ and $25 \mathrm{kGy}$. The measured pressure drop values during filter testing were found to be much less than the inhalation and exhalation resistance limit viz. 343 , and 245 pascals, respectively. All three types of masks showed no significant changes in fit or measurable structural changes when exposed to the $25 \mathrm{kGy}$ doses. The filtering efficiency of surgical and cloth masks are found to be in the range of $15.76 \pm 0.22-22.48 \pm 3.92 \%, 49.20 \pm$ 8.44-60 $\pm 7.59 \%$ and $73.15 \pm 3.73-90.36 \pm 4.69 \%$ for aerosol sizes $0.3-5.0,1.0-5.0$ and 3.0$5.0 \mu \mathrm{m}$ atmospheric aerosols respectively and found to be in the same range when tested with $1.0 \mu \mathrm{m}$ laboratory-generated aerosols for two flow rate, control and irradiated conditions. The $F E$ of surgical masks is more than cloth masks for $102.7 \mathrm{~nm}$ aerosols for $20 \mathrm{~L} \mathrm{~min}^{-1}$ while in case of $90 \mathrm{~L} \mathrm{~min}-1$ flow rate, the $F E$ of cloth masks is more compared to the surgical masks. The FE of cloth and surgical masks increases with the increase of optical diameter and decrease of mobility diameter from least efficiency and MPPS is smaller for high flow rate compared to the low flow rate.

In the case of the N95 mask, the filtering efficiency is found to be more than $95 \%$ for control masks, for both flow rates and atmospheric aerosols $(0.3-5 \mu \mathrm{m})$. The filtering efficiency reduces to about $70 \%$ for most penetrating aerosols $(0.3 \mu \mathrm{m})$ after gamma sterilisation for $20 \mathrm{~L} \mathrm{~min}^{-1}$ flow rate and still lesser with higher flow rate $\left(90 \mathrm{~L} \mathrm{~min}^{-1}\right)$ for ambient aerosols. Further, the filtering efficiency of N95 mask is more than $96 \%$ for laboratory-generated aerosols of $1.0 \mu \mathrm{m}$ 
and $102.7 \mathrm{~nm}$ sizes for both flow rates under unsterilised condition. However, the minimum $F E$, after gamma sterilisation is found to be $84.28 \pm 1.68 \%$ for the flow rate of $20 \mathrm{~L} \mathrm{~min}^{-1}$ and the total tested aerosols of size $>300 \mathrm{~nm}$ while the minimum $F E$ is $89.07 \pm 1.15 \%$ for the tested particles $<300 \mathrm{~nm}$ for $90 \mathrm{~L} \mathrm{~min}^{-1}$ flow rate. The comparison of filtering efficiency of N95 mask for present work and literature shows that, after gamma sterilisation, the mask remain fit but $F E$ found to be reduced for most penetrating particle size, i.e., $0.1-0.3 \mu \mathrm{m}$ aerosols.

The breathability test (pressure drop) and filtering efficiency convey that, more than double layer (or sometimes triple layer) cotton masks could be a potential substitute for medical or surgical masks (not for $\mathrm{N} 95$ masks) for respiratory infected persons in sterile environments. The healthy or common population may use daily double-layered cotton masks in the social community since it is washable and reusable. Since, the particle generated from coughing/sneezing is ranging from 0.1 to $100 \mu \mathrm{m}$ (Yang et al., 2007; Gralton et al., 2011; Lindsley et al., 2012), the surgical and cotton masks significantly reduce (more than $50 \%$ ) the microorganism expelled during coughing/sneezing. Further, even with reduced filtering efficiency, the N95 masks after gamma sterilisation is found to be a better option than the surgical and cloth masks and can be recommended for volunteers, security personnel and health workers. Instead of throwing or disposing of N95 masks after a single use, they still could be reused as N70 masks during these pandemic crises after sterilisation using gamma radiation.

\subsection{Recommendations}

We highlight a few recommendations from the present studies:

- Cotton cloth masks of double-layer (sometimes three-layer) with tight weaves, low porosity and high thread count are preferred for the public. Further, the cotton mask is a potential substitute for the public instead of a surgical mask due to its cost-effectiveness, and it could be reused even after gamma irradiation for decontamination.

- The N95 masks, which are made of electret filtering media, are not recommended for sterilisation or decontamination by ionising radiation, it will compromise the filtering efficiency.

- However, N95 masks after gamma sterilisation are found to be a better option than the surgical and cloth masks and can be recommended for volunteers, security personnel and health workers in case of urgency.

- In the cases of N95, the filtration efficiency is $>84 \%$ for aerosols $>0.3 \mu \mathrm{m}$ and $>95 \%$ for aerosols $<0.3 \mu \mathrm{m}$ for both flow rate and after gamma sterilisation and it is far better from any other type of masks so that it can be reused for few times. It is not recommended for handling COVID-19 patients after sterilisation using gamma radiation.

\section{ACKNOWLEDGEMENT}

The authors acknowledge Dr. C.V. Srinivas, Head, RIAS and Dr. R. Venkatesan, Head, RESD for his encouragement and support to carry out this work. D. Bakkiamis acknowledged for taking optical microscope images. The authors would like to thank the reviewers for their valuable comments and suggestions, which helped to improve the article significantly.

\section{REFERENCES}

Adams, W.C. (1993). Measurement of breathing rate and volume in routinely performed daily activities. Final report. California Air Resources Board 1993, California Environmental Protection Agency: Contract No. A033-205.

ASTM International (2018). Standard specification for performance of materials used in medical facemasks. ASTM F2100-11.

Balazy, A., Toivola, M., Adhikari, A., Sivasubramani, S.K., Reponen, T., Grinshpun, S.A. (2006). Do N95 respirators provide $95 \%$ protection level against airborne viruses, and how adequate are surgical masks? Am. J. Infect. Control. 34, 51-57. https://doi.org/10.1016/j.ajic.2005.08.018

Balazy, A., Toivola, M., Reponen, T., Podgorski, A., Zimmer, A., Grinshpun, S.A. (2005). Manikinbased performance evaluation of N95 filtering-facepiece respirators challenged with 
nanoparticles. Ann. Occup. Hyg. 50, 259-269. https://doi.org/10.1093/annhyg/mei058

Cascella, M., Rajnik, M., Cuomo, A., Dulebohn, S.C., Napoli, R.D. (2020). Features, evaluation and treatment coronavirus (COVID-19). StatPearls Publishing.

Cheng, V.C.C., Wong, S.C., Chuang, V.W.M., So, S.Y.C., Chen, J.H.K., Sridhar, S., To, K.K.W., Chan, J.F.W., Hung, I.F.N., Ho, P.L., Yuen, K.Y. (2020). The role of community-wide wearing of facemask for control of corona virus disease 2019 (COVID-19) epidemic due to SARS-CoV-2. J. Infect. 81, 107-114. https://doi.org/10.1016/j.jinf.2020.04.024

Colbeck, l., Lazaridis, M. (2014). Filtration mechanisms, in: Aerosol science: Technology and applications. ${ }^{\text {st }}$ ed. John Wiley \& Sons: New York. pp. 89-118.

Cramer, A., Tian, E., Yu, S. H., Galanek, M., Lamere, E., Li, Ju., Gupta, R., Short, M. (2020). Disposable $\mathrm{N} 95$ masks pass qualitative fit test but have decreased filtration efficiency after cobalt-60 gamma irradiation. medRxiv 2020.03.28.20043471. https://doi.org/10.1101/2020. 03.28.20043471

Doremalen, N.V., Bushmaker, T., Morris D.H., Holbrook, M.G., Gamble, A., Williamson, B.N., Tamin, A., Harcourt, J.L., Thornburg, N.J., Gerber, S.I., Lloyd-Smith, J.O., De Wit, E., Munster, V.J. (2020). Aerosol and surface stability of SARS-CoV-2 as compared with SARS-CoV-1. N. Engl. J. Med. 382, 1564-1567. https://doi.org/10.1056/NEJMc2004973

Eikenberry, S.E., Mancuso, M., Iboi, E., Phan, T., Eikenberry, K., Kuang, Y., Kostelich, E., Gumel, A.B. (2020). To mask or not to mask: Modeling the potential for face mask use by the general public to curtail the COVID-19 pandemic. Infect. Dis. Model. 5, 293-308. https://doi.org/10.10 16/j.idm.2020.04.001

Feldmann, F., Shupert, W.L., Haddock, E., Twardoski, B., Feldmann, H. (2019). Gamma irradiation as an effective method for inactivation of emerging viral pathogens. Am. J. Trop. Med. Hyg. 100, 1275-1277. https://doi.org/10.4269/ajtmh.18-0937

Feng, S., Shen, C., Xia, N., Song, W., Fan, M., Cowling, B.J. (2020). Rational use of face masks in the COVID-19 pandemic. Lancet Respir. Med. 8: 434-436. ,https://doi.org/10.1016/S2213$2600(20) 30134-X$

Government of India (2015). Radiation processing of food \& medical products, Technical document, 2015, BRIT, India.

Gralton, J., Tovey, E., McLaws, M.L., Rawlinson, W.D. (2011). The role of particle size in aerosolised pathogen transmission. A review. J. Infect. 62: 1-13. https://doi.org/10.1016/j.jinf.2010.11.010

Hinds, W.C. (1999). Properties, behaviour, and measurement of airborne particles. 2nd Ed., John Wiley \& Sons, New York, pp. 182-205.

Ho, K., Lin, L., Weng, S., Chuang, K. (2020). Medical mask versus cotton mask for preventing respiratory droplet transmission in micro environments. Sci. Total Environ. 735, 139510. https://doi.org/10.1016/j.scitotenv.2020.139510

International Atomic Energy Agency (IAEA) (2020). Radiation effective in sterilizing personal protective equipment except for respiratory masks - IAEA. https://www.iaea.org/newscenter/ pressreleases/radiation-effective-in-sterilizing-personal-protective-equipment-except-for-re spiratory-masks-iaea (accessed June 2020)

Juan, C.R., María, D.C.P., Juan, A.T., Santiago, C. (2020). Disposable masks: Disinfection and sterilization for reuse, and non-certified manufacturing, in the face of shortages during the COVID-19 pandemic. Saf. Sci. 129, 104830. https://doi.org/10.1016/j.ssci.2020.104830

Juang, P.S.C., Tsai, P. (2020). N95 respirator cleaning and reuse methods proposed by the inventor of the N95 mask material. J. Emerg. Med. 58, 817-820. https://doi.org/10.1016/j.je mermed.2020.04.036

Kim, J., Chung, Y., Jo, H.J., Lee, N., Kim, M., Woo, S.H., Park, S. Kim, J.W., Kim, H.M., Han, M. (2020). Identification of coronavirus isolated from a patient in Korea with COVID-19. Osong Public Health Res. Perspect. 11, 3-7. https://doi.org/10.24171/j.phrp.2020.11.1.02

Kumar, M., Mazur, S., Ork, B.L., Postnikova, E., Hensley, L.E., Jahrling, P.B., Johnson, R., Holbrook, M.R. (2015). Inactivation and safety testing of Middle East Respiratory Syndrome Coronavirus. J. Virol. Methods 223, 13-18. https://doi.org/10.1016/j.jviromet.2015.07.002

Lee, J., Yoo, D., Ryu, S., Ham, S., Lee, K., Yeo, M., Min, K., Yoon, C. (2019). Quantity, size distribution, and characteristics of cough-generated aerosol produced by patients with an upper respiratory tract infection. Aerosol Air Qual. Res. 19, 840-853. https://doi.org/10.4209/ aaqr.2018.01.0031 
Liao, L., Xiao, W., Zhao, M., Yu, X., Wang, H., Wang, A., Chu, S., Cui, Y. (2020). Can N95 respirators be used after disinfection? How many times? ACS NANO 14, 6348-6356. https://doi.org/10.1 021/acsnano.0c03597

Lin, T., Tseng, C., Huang, Y., Lin, H., Lai, C., Lee, S. (2020). Effectiveness of N95 face piece respirators in filtering aerosol following storage and sterilization. Aerosol Air Qual. Res. 20: 833-843, https://doi.org/10.4209/aaqr.2019.12.0620

Lindsley, W.G., Pearce, T.A., Hudnall, J.B., Davis, K.A., Davis, S.M., Fisher, M.A., Coffey, C.C. (2012). Quantity and size distribution of cough-generated aerosol particles produced by influenza patients during and after illness. J. Occup. Environ. Hyg. 9, 443-449. https://doi.org/10.1080/ 15459624.2012.684582

Man, P.D., Straten B.V., Dobbelsteen, J.V.D., Eijk, A.V.D., Horeman, T., Koeleman, H. (2020). Sterilization of disposable facemasks by means of standardized dry and steam sterilization processes; an alternative in the fight against mask shortages due to COVID-19. J. Hosp. Infect. 105, 356-357. https://doi.org/10.1016/j.jhin.2020.04.001

Morawska, L. (2006). Droplet fate in indoor environments, or can we prevent the spread of infection? Indoor Air 16, 335-347. https://doi.org/10.1111/j.1600-0668.2006.00432.x

Morawska, L., Cao, J. (2020). Airborne transmission of SARS-Cov-2: The world should face the reality. Environ. Int. 139, 105730. https://doi.org/10.1016/j.envint.2020.105730

Moriyama, M., Hugentobler, W.J., Iwasaki, A. (2020). Seasonality of respiratory viral infections. Annu. Rev. Virol. 7, 2.1-2.19. https://doi.org/10.1146/annurev-virology-012420-022445

Pujala, U., Kumar, A., Sujatha, P.N., Subramanian, V., Srinivas, C.V., Baskaran, R. (2019). Experimental studies on morphological properties of sodium combustion, fission product, structural material and mixed aerosols in closed chamber towards Fast Reactor Safety. Ann. Nucl. Energy 130, 319-330. https://doi.org/10.1016/j.anucene.2019.02.044

Santarpia, J.L., Rivera, D.N., Herrera, V., Morwitzer, M.J., Creager, H., Santarpia, G.W., Crown, K.K., Brett-Major, D.M., Schnaubelt, E., Broadhurst, M.J., Lawler, J.V., Reid, S.P., Lowe, J.J. (2020). Transmission potential of SARS-CoV-2 in viral shedding observed the university of nebraska medical centre. Sci. Rep. 10, 12732. https://doi.org/10.1038/s41598-020-69286-3

Subramanian, V., Kumar,A., Pujala, U.,Sujatha P.N., Srinivas C.V., Bhagavatsingh, A., Gopalakrishnan, V., Anathanarayanan, R., Krishnakumar, S., Chandramouli, S., Ashokkumar, A., Baskaran, R., Nashine B.K., Venkatraman B. (2019). Studies on sodium aerosol dispersion experiments in open environment for Fast Reactor Safety. Ann. Nucl. Energy 125, 63-73. https://doi.org/10.1016/j.anucene.2018.10.043

Vincent, J.H. (2007). Aerosol sample applications and field studies, in: Aerosol sampling. Science, Standards, Instrumentation and Applications, New York, pp. 528-529.

Wang, J., Du, G. (2020). COVID-19 may transmit through aerosol. Ir. J. Med. Sci. 189, 1143-1144. https://doi.org/10.1007/s11845-020-02218-2

Worldometer (2020). Coronavirus. https://www.worldometers.info/coronavirus/ (accessed June 2020).

Yang, S., Lee, G.W., Chen, C.M., Wu, C.C., Yu, K.P. (2007). The size and concentration of droplets generated by coughing in human subjects. J. Aerosol Med. 20, 484-494. https://doi.org/10.10 89/jam.2007.0610

Zhang, J., Zheng, C., Xiao, G., Zhou, Y., Gao, R. (2004). Examination of the efficacy of ozone solution disinfectant in inactivating SARS virus. Chin. J. Disinfection. 21, 27-29. (in Chinese) 